\title{
Desempenho tático de jovens jogadores de futebol: comparação entre equipes vencedoras e perdedoras em jogo reduzido
}

\section{Tactical performance of youth soccer players: comparison between winners and losers teams in small sized games}

\author{
SILVA RNB, COSTA IT, GARGANTA JM, MULLER ES, CASTELÃO DP, \\ SANTOS J. Desempenho tático de jovens jogadores de futebol: comparação entre \\ equipes vencedoras e perdedoras em jogo reduzido. R. bras. Ci. e Mov \\ 2013;21(1):75-90.
}

\begin{abstract}
RESUMO: O objetivo deste estudo foi verificar quais comportamentos táticos diferem as equipes vencedoras das perdedoras no jogo em campo reduzido em jovens jogadores de futebol. O desempenho tático de equipes vitoriosas e derrotadas foi comparado através do Sistema de Avaliação Tática no Futebol (FUT-SAT). Três mil, oitocentos e dez ações táticas foram realizadas por 72 jogadores das categorias sub$11(\mathrm{n}=12)$, sub-13 $(\mathrm{n}=12)$ sub-15 $(\mathrm{n}=30)$ e sub-17 $(\mathrm{n}=18)$, de diferentes clubes portugueses. Vinte e quatro equipes foram compostas para a análise, cada equipe disputou um jogo (12 jogos analisados). Cada equipe foi composta por três jogadores de linha, mais o goleiro, não analisado no teste. A análise estatística foi realizada através do software SPSS 17.0 for Windows. Uma análise descritiva e os testes de KolmogorovSmirnov, Qui-quadrado, Mann-Whitney U e o T-teste para amostras independentes foram realizados, e o teste Kappa de Cohen para determinação da confiabilidade da amostra. Considerando 76 variáveis analisadas, 12 apresentaram diferenças significantes entre os jogadores das equipes vitoriosas e derrotadas. Os jogadores das equipes vencedoras apresentaram superioridade na Macro-categoria Ação, nos Princípios táticos defensivos, Equilíbrio e Unidade Defensiva. Na categoria Local da ação no campo de jogo, as equipes vencedoras apresentaram superioridade no número de Ações defensivas realizadas no meio campo defensivo. Na categoria Resultado da ação, nas variáveis Continuar sem a posse de bola, Recuperar a posse de bola e Realizar finalizaça a ao gol as equipes vencedoras apresentaram resultados superiores, enquanto que nas variáveis Perder a posse de bola e Sofrer finalização ao gol a equipes derrotadas apresentaram maiores valores. Na Macro-categoria Performance, a superioridade dos jogadores vencedores foi demonstrada pelo melhor Î́ndice de Performance Tática (IPT) nos princípios Penetração, Unidade Ofensiva e na Fase ofensiva do jogo. Os resultados demonstraram que os jogadores das equipes vencedoras apresentaram superioridade em ambas as fases de jogo.
\end{abstract}

Palavras-chave:Futebol; Tática; Princípios Táticos; FUT-SAT.

\begin{abstract}
The aim of study was to verify what tactical behaviors differ winner from loser teams in small sized games in youth soccer players. The tactical performance of winners and losers teams was compared through of System of Tactical Assessment in Soccer (FUT-SAT). Three thousand eight hundred and eight tactical actions were carried out by seventy-two youth soccer players from the under-11 $(n=12)$, under-13 $(n=12)$, under-15 $(n=30)$ and under-17 $(n=18)$ categories of Portuguese teams. Twenty four teams were composed to analyze, each team carried out one match (12 match analyzed). Each team was composed by three line players with goalkeeper which was not analyzed in test. The statistical analysis was performed thought the SPSS 17.0 software for Windows. A descriptive analyze and the KolmogorovSmirnov, Chi-square, Mann-Whitney U and T-Test tests to the independent samples was carried out, and the Cohen's Kappa test to determining of the sample reability. Considering 76 variables analyzed, 12 presented significant differences among players of winners and loses teams. The players of the winner teams presented superiority in Macro-Category Action, in the Defensive tactical principles, Equilibrium and Defensive Unity. In the category Local of action in the Field, the winner teams presented superiority in the number of defensive actions performed in the defensive midfielder. In the category Result of the action, the variables Keep without the ball, Retrieving the ball possession and Shots on goal the winner teams presented higher results, while in variables Losing the ball possession and Suffering shot on goal the loser teams presented higher results. In the Performance Macro-Category, the superiority of the winners was showed by better Tactical Performance Index (TPI) in the Penetration principles, Offensive Unity, and in the Offensive phase of the game. The results demonstrated that the winner players presented superiority in both stages of the game.
\end{abstract}

Key Words: Soccer; Tactics; Tactical Principles; FUT-SAT.
Roberto N. B. da Silva

Israel T. da Costa ${ }^{2}$

Julio M. Garganta ${ }^{3}$

Ezequiel S. Muller ${ }^{3}$

Daniel P. Castelão ${ }^{4,}$

Julio W. dos Santos

${ }^{1}$ UNESP

${ }^{2}$ Universidade Federal de Viçosa

${ }^{3}$ Faculdade de Desporto da

Universidade do Porto

${ }^{4}$ Secretaria de Estado de Esporte e da Juventude

${ }^{5}$ Universidade Federal de Minas Gerais

Enviado em: 03/10/2012

Aceito em: 17/01/2013

Contato: Roberto Nascimento Braga da Silva - rob-braga@hotmail.com 


\section{Introdução}

O futebol pertence ao grupo dos esportes coletivos, sendo caracterizado como um jogo de cooperação/oposição, no qual duas equipes realizam ações simultâneas sobre a bola em contexto aleatório ${ }^{1}$. Estas características conferem imprevisibilidade às ações, o que implica em constante necessidade de adaptação tática, técnica e física dos jogadores ao contexto apresentado ${ }^{2}$. Em comunhão com esta lógica, constata-se que os estudos relativos ao futebol se centram cada vez mais na dimensão tática, com o intuito de melhor se compreender os processos inerentes à tomada de decisão bem como ao modo como os jogadores e as equipes entendem o jogo ${ }^{3-7}$. Estas análises assumem elevada relevância, já que, segundo Teodorescu ${ }^{8}$ todas as decisões tomadas pelos jogadores durante uma partida, com ou sem a bola, na relação individual ou coletiva, de cooperação ou oposição, são de ordem tática. Como tal, esta dimensão desempenha o papel de matriz unificadora dos comportamentos manifestados, dado que é através da ação tática que as vertentes, psicológica, técnica e física adquirem o devido sentido ${ }^{9}$.

Nos últimos anos, alguns estudos vêm buscando analisar performances de sucesso a fim de identificar fatores responsáveis pela diferenças entre vencedores e vencidos no âmbito do futebol ${ }^{10-13}$. Estes trabalhos visam contribuir para o aumento de conhecimentos e competências de jogadores e treinadores, na busca por melhores resultados. Neste sentido, Grant et.al. ${ }^{14}$ analisaram 36 jogos da Copa do Mundo de Futebol de 1998, tendo avaliado a frequência de chutes, escanteios, faltas, corridas com bola, dribles, cruzamentos, entre outros, com o intuito de diferenciar as equipes desclassificadas na primeira fase, das equipes semifinalistas da competição. Já o estudo de Grant e Williams ${ }^{15}$ comparou as características da posse de bola em equipes bem e mal sucedidas, durante a temporada de 1996/97 da primeira divisão inglesa. Low, Taylor e Williams ${ }^{16}$ utilizaram as partidas da Copa do Mundo de 2002 para avaliarem a diferença entre equipes consideradas de sucesso (semifinalistas) e as sem sucesso (eliminadas na primeira fase da competição). Foram analisados, dribles, cruzamentos, chutes a gol, entre outros aspectos que contribuíram ou não para o alcance da vitória em uma partida.

Este tipo de análise torna-se importante na medida em que facilita o acesso à informação sobre os eventos da partida, possibilitando uma posterior reflexão e uma melhor adequação do treino aos objetivos delineados em relação ao modo de jogar ${ }^{17}$. Deste modo, a análise do jogo ocupa um papel central para a modelação do treino e do modelo de jogo desejado pelo treinador para a sua equipe ${ }^{18-19}$.

Apesar da referida importância, é possível perceber que muitos estudos se restringem a uma análise fragmentada, focando-se apenas os resultados das ações que ocorrem na presença da bola, isto limita a compreensão dos processos ofensivos e defensivos de um confronto futebolístico. Para Garganta e Gréhaigne ${ }^{20}$, tal tipo de análise revela-se insuficiente para explicitar as razões que induzem um desempenho de sucesso das equipes, dado que o futebol é um fenômeno não linear cuja complexidade decorre da interação dos fatores que emergem no jogo, e não de cada um deles quando entendido per se. Isso pode ser constatado empiricamente, por exemplo, através da observação de jogos nos quais nem sempre a equipe com maior número de passes certos, chutes a gol, posse de bola, entre outros, é a vencedora da partida. Além disso, existe uma escassez de estudos dessa dimensão nas categorias de base, uma vez que a maior parte contempla campeonatos profissionais, nos quais atua a elite do futebol mundial. Este fator limita o conhecimento do processo na formação e 
diminui a possibilidade da atuação significativa dos profissionais envolvidos neste contexto.

Neste sentido, o Sistema de Avaliação Tática no Futebol, FUT-SAT, validado por $\operatorname{Costa}^{21}$ busca suprir uma lacuna deixada pela avaliação e a análise fragmentada do futebol. O teste é alicerçado em uma concepção sistêmica e específica dos esportes coletivos. O autor procurou, a partir de um jogo reduzido com a duração de quatro minutos, em que duas equipes compostas por três jogadores mais goleiro se enfrentam, realizar uma análise holística, a partir da avaliação de princípios táticos específicos ofensivos e defensivos do futebol. Esta ferramenta também se faz significante uma vez que os jogos reduzidos podem ser incorporados nos mais diversos objetivos de treino, pois permitem a avaliação e o desenvolvimento das qualidades globais e específicas inerentes ao jogo ${ }^{22-24}$, sendo possível, a partir destes, avaliar e desenvolver as vertentes táticas $^{25-28}$, técnicas ${ }^{29-31}$ e físicas ${ }^{32-34}$.

A partir do contexto apresentado, o presente estudo teve como objetivo analisar o desempenho tático de jovens jogadores de futebol e verificar quais os comportamentos táticos que diferiram as equipes vencedoras das equipes perdedoras no jogo em campo reduzido. Sendo assim, o presente estudo possibilita um maior entendimento da vertente tática em jogadores de futebol jovens e abre um caminho para compreender melhor quais ações táticas são determinantes para o melhor desempenho, o que possibilita uma ação mais ajustada e eficaz no processo de treino por parte dos profissionais envolvidos neste contexto.

\section{Materiais e Métodos}

\section{Amostra}

Foram avaliados 72 jogadores de futebol das categorias: sub-11 ( $\mathrm{n}=12)$, sub-13 $(\mathrm{n}=12)$, sub-15 $(n=30)$ e sub-17 $(n=18)$ que formaram 24 equipes de três jogadores cada, uma vez que o goleiro participou dos jogos, mas não foi considerado na análise. Os jogadores analisados pertenciam a cinco diferentes clubes do futebol português. Todos os indivíduos analisados praticavam sistematicamente o futebol por no mínimo seis meses com uma frequência semanal de dois treinos (sub-11) e progredindo até cinco treinos semanais (sub-17), disputando amistosos e competições de caráter regional. Cada jogador realizou apenas um jogo reduzido, de um total de 12 jogos analisados. Foram descartados os jogos nos quais o resultado final foi o empate. Os jogadores e seus responsáveis foram esclarecidos sobre os objetivos e procedimentos do estudo e deram seu consentimento (Processo $n^{\circ}$. 15449/46/01/11).

\section{Instrumentos e procedimentos para coleta de dados}

$\mathrm{O}$ instrumento utilizado para a análise tática foi o teste FUT-SAT ${ }^{21}$, que consiste em um jogo reduzido, projetado em uma área de 36 metros de comprimento por 27 metros de largura, no qual cada equipe dispõe de três jogadores mais o goleiro, que defende uma baliza de Futebol de Sete (6 metros de largura por 2 metros de altura). O teste tem a duração de 4 minutos e é solicitado aos jogadores que joguem de acordo com as regras do futebol, com exceção do impedimento ${ }^{35}$. Após a divisão das equipes, os jogadores receberam coletes numerados de 1 a 6 para posterior análise. Os jogadores receberam uma breve explicação acerca do teste e, posteriormente, foram-lhes concedidos 30 segundos de adaptação ao mesmo, findos os quais se deu início à avaliação.

O FUT-SAT tem como objetivo avaliar as ações táticas executadas pelos jogadores (com e sem a posse de bola) de acordo com os dez princípios táticos fundamentais do futebol, sendo cinco ofensivos (Penetração, Cobertura Ofensiva, Espaço, Mobilidade e Unidade Ofensiva) e cinco defensivos (Contenção, Cobertura Defensiva, Equilíbrio, 
Concentração e Unidade Defensiva) apresentados por Costa, et. $a l{ }^{36}$. A não aplicação da regra do impedimento no teste se apresenta como uma limitação no que diz respeito à análise das movimentações de Unidade Defensiva, pois estas sofrem influencia da referida regra, contudo é possível se ter a noção de compactação defensiva da equipe mesmo sem esta importante referência. Não foram avaliadas as ações em que o jogador permaneceu sem movimentação, bem como cobranças de faltas, laterais ou escanteios.

As análises dos jogos são realizadas em referência ao protocolo de observação do teste que leva em conta quatro fatores: 1) Realização do princípio tático (RP), 2) Qualidade da realização da ação tática (QR), 3) Localização da realização da ação tática no campo de jogo (LA) e 4) Resultado da ação $(\mathrm{RA})^{37}$. A partir desta análise é calculado o Índice de Performance Tática (IPT) referente aos princípios táticos, fases de jogo e jogo, com base na seguinte equação:

Índice de Performance Tática (IPT) $=\sum$ ações táticas (RP x QR x LA x RA)/número de ações táticas

Quadro 1. Componentes e valores considerados para o cálculo do Índice de Performance Tática ${ }^{20}$

\begin{tabular}{ll}
\hline Componentes & Valores \\
\hline 1) Realização do Princípio (RP) & 1 \\
Fez & 0 \\
Não fez & 10 \\
2) Qualidade da Realização do Princípio (QR) & 5 \\
Bem sucedido & \\
Mal sucedido & \\
3) Localização da Ação no Campo de Jogo (LA) & 2 \\
- Meio Campo Ofensivo & 2 \\
Ações Táticas Ofensivas & \\
Ações Táticas Defensivas & 1 \\
- Meio Campo Defensivo & 1 \\
Ações Táticas Defensivas & \\
Ações Táticas Ofensivas & \\
4) Resultado da Ação (RA) & 5 \\
- Ofensiva & 4 \\
Realizar finalização à baliza & 3 \\
Continuar com a posse de bola & 2 \\
Sofrer falta, ganhar lateral ou escanteio & 1 \\
Cometer falta, ceder lateral ou escanteio & \\
Perder posse de bola & 5 \\
- Defensiva & 4 \\
Recuperar a posse de bola & 3 \\
Sofrer falta, ganhar lateral ou escanteio & 2 \\
Cometer falta, ganhar lateral ou escanteio & 1 \\
Continuar sem posse de bola & \\
Sofrer finalização à baliza & \\
\hline
\end{tabular}

Análise dos Jogos

Para a gravação dos jogos foi utilizada uma câmara digital PANASONIC modelo NV DS35EG. O material de vídeo gravado foi introduzido, em formato digital num computador portátil (marca Positivo modelo Positivo Móbile, processador Intel Dual-Core) via cabo (IEEE 1394), convertendo-os em ficheiros ".avi”.

Para o tratamento das imagens e análise foram utilizados os softwares, Soccer Analyser ${ }^{\circledR}$, específico para o teste, que se destina ao arquivamento das gravações e permite a projeção das referências espaciais sobre o campo de jogo, 
facilitando a avaliação rigorosa do posicionamento e movimentação dos atletas, e, Utilius $V S^{\circledR}$, destinado a análise e arquivamento do material coletado.

\section{Análise estatística}

Os dados recolhidos foram tratados com o auxílio do software SPSS (Statistical Package for Social Science) for Windows®, versão 17.0. Foram realizadas as análises descritivas, de frequência, percentual e variação percentual, média e desviopadrão.

Para facilitar a apresentação dos resultados, os dados foram divididos em duas Macro-Categorias, denominadas Ação e Performance. Na Macrocategoria Ação para a análise das categorias: Princípio tático, Localização da ação no campo de jogo e Resultado da ação, foi utilizado o teste Quiquadrado $\left(\chi^{2}\right)$ (não paramétrico) com nível de significância $\mathrm{p} \leq, 0,05$ por se tratarem de dados categóricos, possibilitando observar a relação entre estas variáveis por parte de vencedores e perdedores. Para a Macro-categoria Performance, nas categorias Índice de performance tática (IPT), Número de ações por princípio (NAP), Percentual de erros (\%) e Localização da ação relativa ao princípio (LARP) foi utilizado o teste de normalidade Kolmogorov-Smirnov para verificar a distribuição dos dados. Para as variáveis que assumiram distribuição normal foi utilizado o teste T-Test para amostras independentes com nível de significância $\mathrm{p} \leq 0,05$. Já para as medidas que assumiram distribuição não normal foi utilizado o teste de Mann-Whitney $U$ com nível de significância $\mathrm{p} \leq 0,05^{38}$.

\section{Análise da confiabilidade}

Para verificar a confiabilidade intra e interavaliadores foram testados três avaliadores, recorrendo-se aos valores do teste Kappa de Cohen a partir do software SPSS (Statistical Package for
Social Science) for Windows (versão 17.0). Neste estudo foi seguida a classificação apresentada por Landis e $\mathrm{Koch}^{39}$ indicando seguintes valores de fiabilidade: 0,00 - pobre; 0,01 a 0,020 - leve; 0,21 a 0,40 - regular; 0,41 a 0,60 - moderada; 0,61 a 0,80 substancial; 0,81 a 100 - perfeita. Todos avaliadores testados obtiveram resultado acima de 0,81 . Também foram reavaliadas 387 ações táticas, obtendo um número de ações reavaliadas maior que $10 \%$ da amostra, valor superior ao apontado pela literatura para a confirmação da confiabilidade intraavaliador $^{40}$.

\section{Resultados}

Os resultados estão apresentados em duas Macro-Categorias, sendo elas: Ação e Performance. A Macro-Categoria Ação, composta por três tabelas, refere-se à frequência e diferença percentual entre os grupos na análise das categorias Princípios táticos (tabela 1), Localização da ação no campo de jogo (tabela 2) e Resultado da ação (tabela 3). Já a Macro-Categoria Performance apresenta os resultados a partir da média e desvio padrão das categorias: Índice de performance tático (IPT), Número de ações por princípio (NAP), Percentual de erro (\%) e Localização da ação referente ao princípio (LARP). Foram realizadas 3810 ações táticas, nos 12 jogos analisados, das quais 1994 foram realizadas pelos jogadores que pertenciam às equipes vencedoras (886 ofensivas e 1108 defensivas) e 1816 foram realizadas pelos jogadores que atuaram nas equipes derrotadas (905 ofensivas e 911 defensivas), os jogos que terminaram empatados foram descartados. (Tabela 1).

No número Total de ações táticas realizadas pelos jogadores foram encontradas diferenças significativas a favor dos vencedores $(\mathrm{p}=0,0039)$, o que indica uma participação mais ativa por parte destes. 
Tabela 1. Princípios Táticos referentes a vencedores e perdedores na realização do FUT-SAT

\begin{tabular}{|c|c|c|c|c|c|}
\hline \multirow{2}{*}{ Categorias e Variáveis } & \multicolumn{2}{|c|}{ Vencedores } & \multicolumn{2}{|c|}{ Perdedores } & \multirow{2}{*}{ Variação Percentual } \\
\hline & $\mathbf{N}$ & $\%$ & $\mathbf{N}$ & $\%$ & \\
\hline \multicolumn{6}{|l|}{ PRINCÍPIOS TÁTICOS } \\
\hline \multicolumn{6}{|l|}{ Ofensivo } \\
\hline Penetração & 118 & 5,92 & 110 & 6,06 & 2,36 \\
\hline Cobertura Ofensiva & 233 & 11,69 & 241 & 13,27 & 13,57 \\
\hline Espaço & 317 & 15,9 & 326 & 17,95 & 12,92 \\
\hline Mobilidade & 85 & 4,26 & 103 & 5,67 & 33,05 \\
\hline Unidade Ofensiva & 133 & 6,67 & 126 & 6,94 & 4,02 \\
\hline \multicolumn{6}{|l|}{ Defensivo } \\
\hline Contenção & 218 & 10,93 & 185 & 10,19 & $-6,82$ \\
\hline Cobertura Defensiva & 56 & 2,81 & 44 & 2,42 & $-13,73$ \\
\hline Equilíbrio & $189^{*}$ & 9,48 & 148 & 8,15 & $-14,02$ \\
\hline Concentração & 186 & 9,33 & 163 & 8,98 & $-3,78$ \\
\hline Unidade Defensiva & $459^{*}$ & 23,02 & 370 & 20,37 & $-11,49$ \\
\hline TOTAL & 1994* & & 1816 & & \\
\hline
\end{tabular}

Em relação aos princípios táticos, foram encontradas diferenças significativas nos princípios táticos defensivos Equilíbrio (p=0,0255) e Unidade Defensiva ( $\mathrm{p}=0$, 0020), com superioridade dos vencedores, que realizaram mais ações de marcação nas zonas laterais a da bola, bem como movimentações com o intuito de aproximar os jogadores mais distantes da bola.

Quanto à Localização das ações no campo de jogo, novamente foram encontradas diferenças significativas apenas em relação às ações defensivas (Tabela 2).

As equipes perdedoras realizaram um maior número de Ações defensivas no campo ofensivo $(\mathrm{p}=0,0303)$, enquanto as vencedoras obtiveram superioridade na realização das Ações defensivas no campo defensivo $(\mathrm{p}<0,0001)$, indicando diferentes posturas defensivas entre as equipes que realizaram o teste.

$\mathrm{Na}$ categoria, Resultado da ação, as equipes vencedoras obtiveram superioridade significativa nas variáveis que demonstraram uma movimentação mais direta com maior número de finalizações e roubadas de bola (Tabela 3 ).

Na categoria, Resultado da ação, as equipes vencedoras obtiveram superioridade significativa nas variáveis: Realizar finalização ao gol ( $\mathrm{p}=0$, 0038), Recuperar a posse de bola $(\mathrm{p}=0,0069)$ e Continuar sem a posse da bola $(\mathrm{p}<0,0001)$. Já as derrotadas obtiveram maiores valores nas variáveis Perder a posse de bola $(\mathrm{p}=0,0064)$ e Sofrer finalização ao gol ( $\mathrm{p}=0,0460)$, o que indica possíveis fatores que contribuíram para obtenção do resultado negativo por parte destas equipes.

Na Macro-categoria Performance, composta pelas tabelas 4, 5, 6 e 7 são apresentados os valores de IPT, NAP, \%E e LARP respectivamente nos dois diferentes grupos.

Os resultados apresentados na Tabela 4 mais uma vez demonstram os possíveis "porquês" de os vencedores terem alcançado resultados positivos no teste. 
Tabela 2. Localização da Ação no campo de jogo referente a vencedores e perdedores na realização do FUTSAT

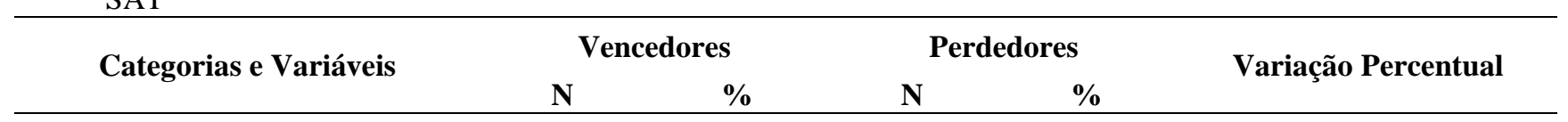

\section{LOCALIZAÇÃO DA AÇÃO NO CAMPO DE JOGO}

Meio Campo Ofensivo

Ações Táticas Ofensivas

$$
20,71
$$

363

19,99

$-3,49$

Ações Táticas Defensivas

23,72

$542 *$

29,85

25,82

$\underline{\text { Meio Campo Defensivo }}$

\begin{tabular}{cccccc} 
Ações Táticas Ofensivas & 544 & 27,28 & 543 & 29,9 & 9,6 \\
Ações Táticas Defensivas & $564 *$ & 28,28 & 368 & 20,26 & $-28,36$ \\
\hline TOTAL & $1994 *$ & 100 & 1816 & 100 & \\
\hline
\end{tabular}

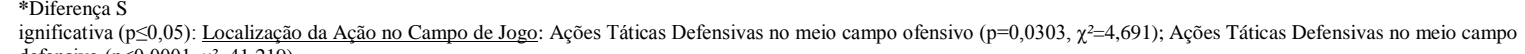
defensivo $\left(\mathrm{p}<0,0001, \chi^{2}=41,219\right)$

Tabela 3. Resultado da Ação referente a vencedores e perdedores na realização do FUT-SAT

\begin{tabular}{|c|c|c|c|c|c|}
\hline \multirow{2}{*}{ Categorias e Variáveis } & \multicolumn{2}{|c|}{ Vencedor } & \multicolumn{2}{|c|}{ Perdedor } & \multirow{2}{*}{ Variação Percentual } \\
\hline & $\mathbf{N}$ & $\%$ & $\mathbf{N}$ & $\%$ & \\
\hline \multicolumn{6}{|l|}{ RESULTADO DA AÇÃO } \\
\hline \multicolumn{6}{|l|}{$\underline{\text { Ofensiva }}$} \\
\hline Realizar finalização ao gol & $121 *$ & 6,07 & 80 & 4,41 & $-27,4$ \\
\hline Continuar com a posse de bola & 630 & 31,59 & 669 & 36,84 & 16,6 \\
\hline Sofrer falta, ganhar lateral ou escanteio & 45 & 2,26 & 32 & 1,76 & $-21,92$ \\
\hline Cometer falta, ceder lateral ou escanteio & 37 & 1,86 & 40 & 2,2 & 18,7 \\
\hline Perder a posse de bola & 53 & 2,66 & $85^{*}$ & 4,68 & 76,1 \\
\hline \multicolumn{6}{|l|}{ Defensiva } \\
\hline Recuperar a posse de bola & $91 *$ & 4,56 & 58 & 3,19 & $-30,02$ \\
\hline Sofrer falta, ganhar lateral ou escanteio & 44 & 2,21 & 35 & 1,93 & $-12,66$ \\
\hline Cometer falta, ceder lateral ou escanteio & 34 & 1,71 & 44 & 2,42 & 42,1 \\
\hline Continuar sem a posse de bola & $841 *$ & 42,18 & 645 & 35,52 & $-15,79$ \\
\hline Sofrer finalização ao gol & 98 & 4,91 & $128 *$ & 7,05 & 43,41 \\
\hline TOTAL & 1994 & 100 & 1816 & 100 & \\
\hline
\end{tabular}

Tabela 4. Médias e desvio padrão - Índice de Performance Tática

\begin{tabular}{lcc}
\multicolumn{1}{c}{ Princípios Táticos } & Vencedores & perdedores \\
\hline$\underline{\text { Ofensivo }}$ & & \\
Penetração & $59,54 \pm 16,95^{*}$ & $49,24 \pm 20,81$ \\
Cobertura Ofensiva & $55,28 \pm 12,04$ & $48,82 \pm 13,11$
\end{tabular}


Mobilidade

Espaço

Unidade Of.

Defensivo

Contenção

Cobertura Defensiva

Equilíbrio

Concentração

Unidade Def.

$\underline{\text { Fase de Jogo }}$

Fase Ofensiva

Fase Defensiva

Jogo
$69,73 \pm 19,31$

$64,00 \pm 17,88$

$46,91 \pm 10,50$

$43,72 \pm 7,34$

$56,25 \pm 17,99 *$

$46,73 \pm 22,32$

$25,22 \pm 8,46$

$25,07 \pm 8,44$

$35,06 \pm 23,36$

$33,99 \pm 20,29$

$27,02 \pm 13,02$

$24,5 \pm 16,29$

$27,04 \pm 9,58$

$28,01 \pm 9,57$

$25,24 \pm 7,35$

$23,06 \pm 6,40$

$48,62 \pm 8,26$

$25,61 \pm 5,17$

$24 \pm 3,99$

$38,9 \pm 6,54$

$35,92 \pm 4,05$

*Diferença Significativa ( $\mathrm{p}<0,05)$ : Índice de Performance Tática: Penetração ( $\mathrm{p}=0,036 ; \mathrm{t}=-1,828)$; Unidade Ofensiva ( $\mathrm{p}=0,012 ; \mathrm{t}=-2,290)$; Fase Ofensiva ( $\mathrm{p}=0,003$; $\mathrm{t=-2,770)}$

Os IPTs referentes aos princípios ofensivos Penetração $\quad(\mathrm{p}=0,036)$, Unidade Ofensiva $(\mathrm{p}=0,012)$ e Fase ofensiva de jogo $(\mathrm{p}=0,003)$, apresentam diferenças significativas a favor dos vencedores. Estes resultados indicam que os jogadores destas equipes obtiveram êxito nas ações de progressão do portador da bola, e uma melhor compactação ofensiva, aproximando os jogadores do centro de jogo nas ações ofensivas. Estes fatores contribuíram para o alcance do maior IPT na Fase ofensiva de jogo.

São apresentados abaixo os Números de ações por princípio (tabela 5).
Na tabela 5 é possível obervar que os valores de NAP não apresentaram diferenças significativas

A tabela 6 apresenta o percentual de erros de cada princípio tático realizado por vencedores e perdedores.

$\mathrm{O} \% \mathrm{E}$ dos dois grupos analisados apresentou maiores valores dos perdedores em todos os princípios táticos com exceção do princípio da Mobilidade, contudo, não foram encontradas diferenças significativas, sendo possível afirmar que o $\% \mathrm{E}$ não foi decisivo na obtenção da vitória.

Tabela 5. Médias e desvio padrão - Número de ações por princípio

\begin{tabular}{lcc}
\hline \multirow{2}{*}{ Princípios Táticos } & \multicolumn{2}{c}{ NAP } \\
& vencedores & Perdedores \\
\hline$\underline{\text { Ofensivo }}$ & & \\
Penetração & $3,28 \pm 1,95$ & $3,08 \pm 1,93$ \\
Cobertura Ofensiva & $6,47 \pm 3,31$ & $6,26 \pm 40$ \\
Mobilidade & $2,36 \pm 1,93$ & $3,03 \pm 3,30$ \\
Espaço & $8,81 \pm 3,91$ & $10,24 \pm 6,16$ \\
Unidade Of. & $3,69 \pm 2,94$ & $3,21 \pm 2,96$ \\
Defensivo & & \\
Contenção & $6,06 \pm 2,94$ & $4,73 \pm 2,61$ \\
Cobertura & $1,56 \pm 1,36$ & $1,26 \pm 1,14$ \\
Defensiva & $5,25 \pm 2,56$ & $4,03 \pm 2,04$ \\
Equilíbrio &
\end{tabular}




\begin{tabular}{lcc} 
Concentração & $5,17 \pm 3,24$ & $4,42 \pm 2,91$ \\
Unidade Def. & $12,75 \pm 4,99$ & $12,08 \pm 3,90$ \\
Fase de Jogo & & \\
Fase Ofensiva & $24,61 \pm 5,25$ & $25,82 \pm 9,53$ \\
Fase Defensiva & $30,78 \pm 10,73$ & $26,52 \pm 5,64$ \\
Jogo & $55,39 \pm 11,23$ & $52,33 \pm 9,85$ \\
\hline
\end{tabular}

Tabela 6. Médias e desvio padrão - Percentual de Erros

\begin{tabular}{lcc}
\hline \multicolumn{1}{c}{ Princípios Táticos } & Vencedor & \% E \\
\hline$\underline{\text { Ofensivo }}$ & & perdedor \\
Penetração & $9,76 \pm 20,92$ & $14,18 \pm 29,21$ \\
Cobertura Ofensiva & $6,96 \pm 14,68$ & $7,64 \pm 17,53$ \\
Mobilidade & $0,81 \pm 4,49$ & 0 \\
Espaço & $4,73 \pm 10,85$ & $8,93 \pm 15,30$ \\
Unidade Of. & $33,47 \pm 30,96$ & $40,9 \pm 35,88$ \\
Defensivo & & \\
Contenção & $60,98 \pm 24,75$ & $69,02 \pm 21,74$ \\
Cobertura Defensiva & $36,31 \pm 41,40$ & $48,76 \pm 43,94$ \\
Equilíbrio & $56,00 \pm 30,86$ & $67,02 \pm 31,92$ \\
Concentração & $28,56 \pm 24,61$ & $36,36 \pm 29,29$ \\
Unidade Def. & $49,90 \pm 29,45$ & $62,62 \pm 26,93$ \\
Fase de Jogo & & \\
Fase Ofensiva & $11,09 \pm 8,36$ & $12,48 \pm 9,57$ \\
Fase Defensiva & $49,44 \pm 14,43$ & $60,48 \pm 14,22$ \\
Jogo & $31,23 \pm 8,35$ & $35,73 \pm 6,95$ \\
\hline
\end{tabular}

Na análise da Tabela 7, a LARP também não apresentou nenhuma diferença significativa entre equipes vencedoras e perdedoras na realização do teste.

Tabela 7. Médias e desvio padrão - Localização da Ação em Relação ao Princípio

\begin{tabular}{lcc}
\hline \multicolumn{1}{c}{ Princípios Táticos } & \multicolumn{2}{c}{ LARP } \\
\hline$\underline{\text { Ofensivo }}$ & vencedor & perdedor \\
Penetração & $1,52 \pm 1,48$ & $1,56 \pm 1,41$ \\
Cobertura Ofensiva & $3,60 \pm 2,86$ & $4,38 \pm 3,50$ \\
Mobilidade & $0,45 \pm 0,72$ & $0,48 \pm 0,97$ \\
Espaço & $6,47 \pm 3,48$ & $8,09 \pm 5,39$ \\
Unidade Of. & $1,47 \pm 1,56$ & $1,85 \pm 2,24$ \\
Defensivo & & \\
Contenção & $3,40 \pm 2,40$ & $2,23 \pm 2,16$ \\
Cobertura Defensiva & $0,71 \pm 0,90$ & $0,51 \pm 0,51$ \\
Equilíbrio & $2,08 \pm 1,96$ & $1,53 \pm 1,76$ \\
Concentração & $3,44 \pm 2,55$ & $2,44 \pm 2,67$ \\
Unidade Def. & $5,89 \pm 3,82$ & $4,86 \pm 2,36$ \\
Fase de Jogo & &
\end{tabular}


Fase Ofensiva

Fase Defensiva

Jogo
$13,51 \pm 5,80$

$15,08 \pm 8,51$

$28,22 \pm 10,33$
$16,22 \pm 7,89$

$11,14 \pm 6,00$

$26,62 \pm 9,12$

\section{Discussão}

O presente estudo teve como objetivo verificar quais comportamentos táticos diferiram entre as equipes vencedoras e as perdedoras no jogo em campo reduzido, em jovens jogadores de futebol. A partir dos resultados verificou-se que 12 das 76 variáveis analisadas apresentaram diferenças significativas. Apesar da validade do teste, a não utilização da regra do impedimento, duração e o número de jogadores podem ser vistos como limitações do estudo no que se refere à generalização para o jogo oficial. No entanto, quando comparamos o comportamento tático dos jogadores no teste, é possível distinguir diferenças sutis no desempenho tático entre os jogadores e equipes $^{21}$. No entanto, as análises de jogos de $5 \times 5$, $7 \times 7$ e 11x11 a partir dos princípios táticos aqui apresentados, fornecerão ainda mais informações sobre o desempenho tático de jogadores de futebol.

Na categoria Princípios táticos, analisada na Macro-Categoria Ação, observa-se que as equipes derrotadas realizaram um menor número de ações em todos os princípios táticos defensivos, sendo que nos princípios Equilíbrio e Unidade Defensiva foram encontradas diferenças significativas a favor das equipes vencedoras. As ações do princípio Equilíbrio evidenciam que as equipes vencedoras realizaram movimentações que buscam a igualdade ou superioridade numérica nas zonas laterais a da bola, com o intuito de aumentar a segurança em relação à própria baliza e transmitir confiança aos jogadores que realizam a Contenção e Cobertura Defensiva $^{37}$. As ações apresentadas pelos jogadores das equipes vencedoras estão de acordo com Garganta ${ }^{41}$, segundo o qual, uma equipe deve buscar, em sua defesa, cobrir e reforçar permanentemente o eixo central do campo, além de "enviar" o ataque adversário para as zonas laterais, e de menos perigo no campo, além de possuir um número ideal de jogadores entre a bola e a baliza. Além disso, as ações de Unidade Defensiva tem como intuito a aproximação das linhas defensivas da equipe. Essa aproximação não apenas diminui o espaço entre as linhas de defesa dificultando o ataque, como possibilita que os jogadores estejam mais próximos ao portador da bola, possibilitando uma ação mais efetiva dos mesmos ${ }^{42}$. Estas movimentações exigem um auto nível de organização da equipe, pois por serem realizadas pelos jogadores mais distantes do centro de jogo torna-se necessária a existência de uma consciência coletiva em relação aos $\operatorname{mesmos}^{36}$. O FUT-SAT, composto pelo jogo reduzido de $3 \times 3$ jogadores mais goleiros facilita estas ações uma vez que, exige uma coordenação coletiva entre 3 jogadores de uma mesma equipe e não 11 como em um jogo de futebol oficial, contudo, a não aplicação da regra do impedimento dificulta esta ação dos jogadores, uma vez que o benefício de compactar as linhas defensivas está implícito no jogo e não explícito pela regra. Apesar desta limitação, este processo de análise se torna relevante em categorias de formação e no presente estudo permitiu observar a superioridade apresentada na organização defensiva por parte das equipes vencedoras.

O resultado encontrado na categoria Localização da ação no campo de jogo se assemelha ao encontrado no estudo de Costa et $a l .{ }^{43}$ que compararam duas equipes sub-15 na realização do teste FUT-SAT. Porém, ao contrário do estudo citado, o presente trabalho registrou-se 
superioridade da defesa em bloco baixo em relação à defesa em bloco alto. Este tipo de disposição defensiva pode ter obtido melhores resultados devido à ineficácia das movimentações defensivas no campo do adversário, além da não realização de movimentações defensivas em bloco, que segundo Garganta e Pinto ${ }^{42}$ caracterizam um modelo de jogo avançado. Como os jogadores estão posicionados longe da baliza, as movimentações necessitam de uma coordenação maior, caso contrário haverá lugar a uma ampliação expressiva do espaço efetivo de jogo $^{44}$, o que dificulta as movimentações e marcações por parte dos jogadores que defendem. Este tipo de marcação pode também facilitar a utilização das jogadas em profundidade pela equipe atacante, devido ao maior espaço entre o último jogador da equipe que defende e a respetiva linha de fundo. Grant et. al. ${ }^{14}$ apontam para esta perspectiva, quando observam que mais gols são marcados quando a bola é recuperada em uma área defensiva, devido ao maior espaço para organização das movimentações ofensivas. Porém, em grande parte, tal é determinado pelo modelo de jogo da equipe e pela proficiência dos seus jogadores. Repare-se, por exemplo, que para uma defesa em bloco alto é condição fundamental uma noção apurada de marcação dos jogadores mais adiantados da equipe, atributo não facilmente encontrado nas categorias de formação.

$\mathrm{Na}$ categoria Resultado da ação, a superioridade das equipes vencedoras nas variáveis Continuar sem a posse, Recuperar a posse de bola e Realizar finalização ao gol, se assemelha ao estudo de Szwarc ${ }^{45}$, que, de uma série de fatores analisados, apresenta que a frequiência e precisão dos chutes a gol, as recuperações de bola em situações diretas contra o oponente, e a proteção efetiva da própria baliza foram os mais significativos. Estes parecem ser fatores decisivos que permitem a organização defensiva da equipe, bem como possibilitam organizar uma transição ofensiva adequada de modo a aproveitar os espaços concedidos pelo adversário para criar situações de gol. Quanto ao maior número de ações sem a posse de bola, o estudo de Lago e Martin ${ }^{46}$ permite constatar que as equipes têm maior posse de bola quando estão perdendo ou empatando, e não quando estão à frente no placar, comportamento este também encontrado no presente estudo. Percebe-se, portanto, que as equipes vencedoras optaram por uma postura centrada em uma defesa eficaz utilizando-se das conquistas de bola para se organizarem em transições ofensivas objetivas buscando a finalização ao gol. A eficácia deste comportamento tático é reforçada pelo estudo realizado por Hughes e Franks ${ }^{47}$ no qual as movimentações diretas resultaram em um maior número de finalizações em comparação com o jogo de posse de bola. Segundo Garganta ${ }^{41}$, este tipo de comportamento deve ser incentivado nas categorias de base, buscando evitar "abuso" do jogo indireto e a perda do foco no objetivo central, o gol. Deve referir-se, contudo, que este autor destaca a importância maior de se conseguir um equilíbrio entre as movimentações diretas e indiretas, em função dos problemas que vão ocorrendo em uma partida e que implicam numa gestão inteligente, fase a fase e momento a momento.

A análise da Macro-categoria Ação evidencia uma importante relação entre as suas três subcategorias. Todas apresentaram diferenças significativas entre vencedores e perdedores, sendo estas mais evidentes na fase defensiva do jogo. A superioridade das equipes vencedoras na realização dos princípios Equilíbrio e Unidade Defensiva pode ter sido induzida pela defesa em 
bloco baixo realizada por estas equipes, o que permite supor que estes resultados influenciaram diretamente o maior número de recuperações de bolas e o maior número de finalizações a gol por parte destas equipes.

$\mathrm{Na}$ análise da Macro-Categoria Performance, os resultados apresentados apontam novamente para a superioridade das equipes vencedoras na realização do FUT-SAT. A superioridade no IPT Penetração por parte dos vencedores indica que apesar do número semelhante de ações táticas realizadas pelos dois grupos analisados, as equipes vencedoras obtiveram maior sucesso na realização deste princípio. Neste aspecto o estudo apresentado proporciona uma mais-valia em relação ao estudo de Low, Taylor e Williams ${ }^{16}$ que ao analisar as equipes de sucesso na copa do mundo de 2002, encontraram superioridade no número de dribles, corridas verticais com bola e penetrações na defesa adversária por parte das equipes de sucesso. Porém, os mesmos não levam em consideração o resultado final e o sucesso ou não das jogadas, primando pela analise quantitativa em detrimento da análise qualitativa. Estes resultados também permitem supor que esta superioridade induziu um maior número de finalizações por parte dos vencedores, fator este também encontrado no estudo citado.

Já a superioridade encontrada no IPT Unidade Ofensiva remete a uma movimentação ofensiva conjunta, que facilita a troca de bola entre os jogadores. Este índice indica que os jogadores se movimentaram em "bloco", diminuindo a distância entre suas linhas longitudinais e transversais, movimentações que tendem a aumentar a confiança dos jogadores presentes no centro de jogo para a criação de desequilíbrios e instabilidades na organização defensiva adversária $^{37}$. A partir da Unidade
Ofensiva também são criadas um maior número de linhas de passe seguras, sendo possível que a equipe que detém a bola canalize o ataque para os espaços mais vulneráveis na defesa adversária característica estas que, segundo Garganta ${ }^{41}$ constituem regras de ação para tornar mais eficaz a fase ofensiva de uma equipe.

Por fim, a partir da análise da Tabela 2, para a Macro-Categoria Performance, é possível perceber que os jogadores das equipes vencedoras apresentam um maior IPT em todos os princípios táticos com exceção a Concentração, além de um menor \% E em todos os princípios com exceção à Mobilidade. Apesar do baixo número de variáveis que apresentam diferenças significativas nesta Tabela, quando "somadas", estas pequenas diferenças podem vir a influenciar de maneira efetiva o resultado final dos jogos ${ }^{20}$.

Em conjunto, os resultados observados contribuem para investigadores, treinadores e jogadores na compreensão dos comportamentos táticos intervenientes nos resultados de jogo reduzido. Isto culmina em uma atuação mais eficiente e eficaz dos profissionais envolvidos neste contexto que podem organizar o processo de treino tendo como referencia as virtudes $\mathrm{e}$ deficiências táticas de seus jogadores em jogos condicionados e de como estas influenciam no resultado final das partidas.

\section{Conclusões}

Os jogadores das equipes vencedoras apresentaram superioridade em relação aos perdedores em princípios táticos específicos da fase defensiva e ofensiva de jogo, além de uma postura tática distinta. Os vencedores optaram pela defesa em bloco baixo, indicado pelo maior número de Ações defensivas no meio campo defensivo, postura esta que apresentou maior eficácia neste estudo. Quanto à frequência de 
realização, as equipes vencedoras apresentaram superioridade nos princípios defensivos Equilíbrio e Unidade Defensiva, o que refletiu no maior número de Recuperação da posse de bola por parte destas. Também houve diferenças significativas em favor das equipes vencedoras nas variáveis Continuar sem a posse de bola e Realizar finalização ao gol, o que indica que estas equipes optaram por movimentações diretas quando na posse da bola. Na fase ofensiva, a superioridade das equipes vencedoras foi constatada pelos maiores IPTs nos princípios ofensivos Penetração, Unidade Ofensiva e Fase ofensiva de jogo.

Tomando todos os resultados em conjunto, as equipes vencedoras apresentaram superioridade no comportamento e desempenho tático em relação às derrotadas em ambas as fases de jogo. Como limitações do estudo e a possibilidade de desenvolvimento em futuro estudos podemos destacar a inclusão da regra do impedimento, bem como a análise de jogos de 5x5, 7x7 e 11×11 a partir dos princípios táticos empregados no FUTSAT.

\section{Referências}

1. Garganta J. Para uma teoria dos jogos desportivos colectivos. In: Graça A, Oliveira J, editors. $\mathrm{O}$ ensino dos jogos desportivos. FCDEFUP: CEJD; 1998. p. 11-25.

2. Castelo J. Futebol Modelo TécnicoTático do Jogo. Universidade Técnica de Lisboa: FMH; 1994.

3. Tavares F, Greco P, Garganta J. Perceber, conhecer, decidir e agir nos jogos desportivos coletivos. In: Tani $G$, Bento JO, Petersen RDS, editors. Pedagogia do desporto. Rio de Janeiro: Guanabara Koogan; 2006. p. 28498.

4. Costa L, Nascimento J. O ensino da técnica e da tática: Novas abordagens Metodológicas. Maringáv. 2004;15(2):49-56.

5. Garganta J. Modelação táctica do jogo de futebol - estudo da organização da fase ofensiva em equipas de alto rendimento. Porto1997.

6. Giacomini DS, Greco PJ. Comparação do conhecimento tático processual em jogadores de futebol de diferentes categorias e posições. Revista Portuguesa de Ciências do Desporto. 2008;8:126-

7. Memmert D. Testing of tactical performance in youth elite soccer. J Sport Sci Med 2010;9(2):199-205.

8. Teodorescu L. Problemas da teoria e metodologia nos jogos desportivos. Lisboa: Livros Horizontes Lta; 1984.

9. Oliveira J. Conhecimento específico em futebol. Contributos para a definição de uma matriz dinâmica do processo ensinoaprendizagem do jogo. Porto2004.

10. Horn R, Williams AM. A look ahead to world cup 2002: what do the last 40 years tell us. Coaching. 2002;5(2).

11. Carron A, Bray SR, Eys MA. Team cohesion and team success in sport. Journal of Sports Sciences. 2002;1(2):119-26.

12. Lago C. Are winners different from losers? Performance and chance in the FIFA World Cup Germany 2006. International Journal of Performance Analysis in Sport. 2007;7(2):36-47.

13. Ostojic SM. Characteristics of elite and non-elite Yugoslav soccer players: Correlates of success. Journal of Sports Science and Medicine. 2003;2:34-5.

14. Grant A, Williams M, Reilly T, Borrie A. Analysis of the successful and unsuccessful teams in the 1998 world cup. Coaching. 1998;2(1).

15. Grant A, Williams M. Analysis of Possession in 1996-97 Premier League Matches. Exercise Science. 1997;1(1).

16. Low D, Taylor S, Williams M. A quantitative analyses of successful and unsuccessful teams. Insight. 2002;5(4).

17. Hughes C, Franks I. Notational analysis of sport. London: E. \& F.N Spon; 1997.

18. Garganta J. Analisar o jogo nos jogos desportivos colectivos - uma preocupação comum ao treinador e ao investigador. Horizonte. 1998;14(83):7-14.

19. Carling C. Getting the most out of video and match analysis. Coaching. 2001;5(1).

20. Garganta J, Grehaigne J. Abordagem Sistêmica do Futebol: Moda ou Necessidade? Revista Movimento. 1999;1(10):40-50. 
21. Costa I. Comportamento Tático no Futebol: Contributo para a Avaliação do Desempenho de Jogadores em situação de Jogo Reduzido. Porto 2010.

22. Graça A. Os comos e quandos no ensino dos jogos. In: Graça. A, Oliveira J, editors. O ensino dos jogos desportivos 3ed. Faculdade de Ciências do Desporto e de Educação Física da Universidade do Porto: Rainho \& Neves Lda; 1998. p. 27-34.

23. Castelo J, Barreto H, Alves F, Santos P, Carvalho J, Vieira J. Metodologia do treino desportivo. Faculdade de Motricidade Humana2000.

24. Veleirinho AC. O Jogo Reduzido. Pertinência e possibilidades no ensino dos jogos desportivos coletivos. Estudo dos Jogos Desportivos. Concepções, Metodologias e Instrumentos. Faculdade de Ciências do Desporto e de Educação Física da Universidade do Porto: Multitema; 1999. p. 69-76.

25. Figueira F, Greco P. Futebol: um estudo sobre a capacidade tática no processo de ensinoaprendizagem-treinamento. Rev Bras Futebol. 2008;1(2):53-65.

26. Costa I. Análise e Avaliação do Comportamento Tático no Futebol. Revista de Educação Física/UEM. No prelo.

27. Sisto F, Greco P. Comportamento tático nos jogos esportivos coletivos. Revista Paulista de Educação Física. 1995;9(1):63-8.

28. Souza CRBC. Análise do Comportamento Tático no Futebol: Estudo em função do estatuto posicional e Análise da eficácia das sessões de treino sobre o aprendizado de jogadores. Porto 2010.

29. Grant A, Williams M, Dodd R, Johnson S. Physiological and Technical Analysis of 11v11 and 8v8 Youth Football Matches. Insight. 1999;3:29-30.

30. Matta M, Greco P. O processo de Ensino-Aprendizagem-Treinamentto da técnica esportiva aplicada ao futebol. Revista Mineira de Educação Física. 1996;4(2):34-50.

31. Platt D, Maxwell A, Horn R, Williams M, Reilly T. Physiological and Technical Analysis of $3 \mathrm{v} 3$ and $5 \mathrm{v} 5$ Youth Football Matches. Coaching. 2001;4(4):42-5.

32. Impellizzeri F, Marcora S, Castagna C, Reilly T, Sassi A, AIaia F, et al. Physiological and Performance Effects of generic versus specific aerobic training in soccer players. Internacional Journal of Sports Medicine. 2006;27(6):483-92.
33. Reilly T. An ergonomics model of soccer training process. Journal of Sports Sciences. 2005;23(6):561-72.

34. Rampinini E, Impellizzeri F, Castagna C, ABT G, Chamari K, Sassi A, et al. Factors influencing physiological responses to smallsided soccer games. Journal of Sports Sciences. 2007;25(6):659-66.

35. FIFA. Laws of the Game 2008/2009. Zurich: Fédération Internationale de Football Association; 2008.

36. Costa I, Garganta J, Greco P, Mesquita I. Princípios Táticos do Jogo de Futebol. Revista Motriz. 2009;15(3):1-15.

37. Costa I, Garganta J, Greco P, Mesquita I. Avaliação do Desempenho Tático no Futebol: Concepção e Desenvolvimento da Grelha de Observação do Teste "GR3-3GR". Rev Mineira Educação Fís 2009;17(2):36-64.

38. Pestana MH, Gageiro JN. Análise de dados para ciências sociais: a complementaridade do SPSS. Lisboa: Edições Sílabo; 2003.

39. Landis JR, Koch GC. The measurement of observer agreement for categorical data. Biometrics. 1977;33:1089-91.

40. Tabachnick B, Fidell L. Using Multivariate Statistics. 5 ed. New York: Harper \& Row Publishers; 2007.

41. Garganta J. Competências no ensino e treino de jovens futebolistas. Revista digital [serial on the Internet]. 2002; 8: Available from: http://www.efdeportes.com.

42. Garganta J, Pinto J. O ensino do futebol. In: Graça A, Oliveira J, editors. O ensino dos jogos desportivos. Faculdade de Ciências do Desporto e de Educação Física da Universidade do Porto: Rainho \& Neves Lda; 1994. p. 95-136.

43. Costa I, Garganta J, Greco P, Mesquita I, Castelão D, Müller E, et al. Análise do comportamento e do desempenho táctico de jogadores de futebol sub-15: estudo comparativo entre dois clubes portugueses. Revista Digital [serial on the Internet]. 2010; 14(141): Available from: http://www.efdeportes.com/.

44. Costa I, Garganta J, Greco P, Mesquita I, Silva B, Müller E, et al. Análise do comportamento tático em jogos reduzidos de futebol: estudo comparativo entre pisos sintético e pelado. Revista Digital [serial on the Internet]. 2009.

45. Szwarc A. Effectiveness of brazilian and german teams and the teams defeated by them 
during the 17th Fifa World Cup. Kinesiology. 2004;36(4):83-9.

46. Lago C, Martin R. Determinants of possession of the ball in soccer. J Sports Sci 2007;25(9):969-74.

47. Hughes M, Franks I. Analysis of pass sequences, shots and goals in soccer. Journal of Sports Sciences. 2005;23(5):509-14. 